J. Dairy Sci. 98:2345-2355

http://dx.doi.org/10.3168/jds.2014-8380

(C) American Dairy Science Association ${ }^{\circledR}, 2015$.

\title{
A longitudinal study of factors influencing the result of a Mycobacterium avium ssp. paratuberculosis antibody ELISA in milk of dairy cows
}

\author{
S. W. F. Eisenberg, ${ }^{* 1,2}$ E. Veldman, ${ }^{* 2}$ V. P. M. G. Rutten, †‡ and A. P. Koets ${ }^{\star} \dagger$ \\ *Department of Farm Animal Health, and \\ †Division of Immunology, Department of Infectious Diseases and Immunology, Faculty of Veterinary Medicine, Utrecht University, \\ $3584 \mathrm{CL}$ Utrecht, the Netherlands \\ ‡Department of Veterinary Tropical Diseases, Faculty of Veterinary Science, University of Pretoria, Onderstepoort, 0110 South Africa
}

\begin{abstract}
The influence of milk yield and milk composition on the diagnosis of Mycobacterium avium ssp. paratuberculosis (MAP) by milk ELISA in the context of the total IgG secretion patterns in milk throughout lactation and serum concentrations were investigated. A 2-yr trial was performed in which 1,410 dairy cows were sampled monthly and MAP milk ELISA status and milk yield and composition were determined. Data were analyzed by mixed model analysis. Milk yield was found to significantly influence ELISA results expressed as sample-to-positive $(\mathrm{S} / \mathrm{P})$ ratios. For each 5 -kg increase in milk, the $\mathrm{S} / \mathrm{P}$ ratio has to be multiplied by 0.89 ; therefore, high milk yield can change the MAP milk ELISA outcome of a cow in early infection from positive to negative. Parity influenced ELISA outcome significantly, indicating that cows with a parity $>1$ are more likely to be identified by milk testing. Also, herd was an important predictor, showing that herd prevalence influences the milk ELISA strongly. Other factors influencing the $\mathrm{S} / \mathrm{P}$ ratios were protein concentration, somatic cell count, and days in milk. The IgG concentration and mass excreted per day were determined longitudinally in a subset of 41 cows of which samples and data of a complete lactation were available. Again, the IgG concentration in milk was mainly influenced by milk yield. The total IgG mass secreted per day in milk was found to be relatively constant, with a mean of $8.70 \pm 5.38 \mathrm{~g}$ despite an increasing IgG concentration in serum at the same time. The variation of $\operatorname{IgG}$ concentration in milk can be mainly attributed to dilution through changes in milk yield. This supports the assumption that concentrations of MAP-specific antibodies are influenced by changes in milk yield similarly. In conclusion, we confirmed that antibody concentrations,
\end{abstract}

Received May 19, 2014.

Accepted December 30, 2014.

${ }^{1}$ Corresponding author: s.w.f.eisenberg@uu.nl

${ }^{2}$ Both authors contributed equally to this work. and therefore MAP ELISA outcome, were influenced by milk yield, herd, and parity. To enhance performance, milk ELISA tests should either be performed in early or late lactation, when milk yield is low. From a management perspective, sampling should be done during early lactation before cows are bred again. Based on the slow progressive infection dynamics, only first-parity cows should be preferentially tested at the end of their first lactation to avoid false-negative results.

Key words: MAP milk ELISA, milk yield, immunoglobulin $\mathrm{G}$ concentration, dairy cow

\section{INTRODUCTION}

Paratuberculosis caused by Mycobacterium avium ssp. paratuberculosis (MAP) is an important concern in dairy cattle farming around the world. Paratuberculosis is characterized as an infectious disease that slowly develops a chronic enterocolitis, regional lymphangitis, and lymphadenitis causing progressive weight loss (Clarke, 1997). High economic losses due to disease have been described; therefore, disease-control programs at farm level were developed (Ott et al., 1999; Villarino et al., 2011). In addition, paratuberculosis is suspected to be a public health concern due to incomplete elimination of MAP by current milk pasteurization methods and the fact that MAP was cultured from blood of Crohn's disease patients, indicating a potential role in the pathogenesis of this chronic inflammatory disease (Naser et al., 2004).

Besides management measures to prevent transmission of paratuberculosis, one of the main issues in control programs is the identification of infected cows in a herd (Nielsen, 2008). Available tests have proven to lack sensitivity, especially in the early stages of the disease (Clark et al., 2008; Nielsen, 2008). Fecal culture is time consuming, labor intensive, and therefore costly compared to other diagnostic tests, and intermittent shedding of bacteria makes a negative result unreliable (Clark et al., 2008; Nielsen, 2008). A fecal PCR can be performed and, although it is much faster, it faces 
similar limitations as the fecal culture (Sweeney, 2011). Progression of disease from asymptomatic to clinical is positively associated with an increase of the humeral immune response; therefore, the milk ELISA has been described as a useful tool to identify infectious animals (Chiodini, 1996; Lombard et al., 2006; Nielsen, 2008). As the interpretation of the ELISA is based on a cutoff value, it is important to know what other factors besides disease status influence the test result. Earlier studies showed changes in MAP-specific antibody concentrations throughout lactation using a commercial MAP ELISA, indicating that DIM and milk yield influence the ELISA test result (Nielsen et al., 2002a). A dilution of total antibody concentration of colostrum after parturition due to the start of milk production has been described (Baumrucker et al., 2010; Morin et al., 2010). A similar characteristic holds true for antibodies against MAP, with the odds of detecting MAP antibodies being 130 times higher at 0 DIM as compared with 4 DIM (Zervens et al., 2013). Furthermore, milk yield was shown to be negatively associated with milk ELISA outcome for MAP but also for Ostertagia ostertagi (Sanchez et al., 2004; Lombard et al., 2006; Nielsen and Toft, 2012). Therefore, it was recommended to include milk yield in the interpretation of ELISA results to enhance its diagnostic value (Sanchez et al., 2004; Nielsen and Toft, 2012). Another research group developed a regression model on serum ELISA results using cowspecific information to enhance the accuracy of diagnosis (Norton et al., 2010). Longitudinal information about factors influencing the variation of $\mathrm{IgG}$ in milk throughout lactation in dairy cows is scarce (Sanchez et al., 2004), especially information regarding the relation of IgG and MAP-specific antibody variation.

Therefore, our longitudinal study addressed 3 objectives. The first objective was to describe the kinetics of MAP antibody ELISA sample-to-positive ratio $(\mathbf{S} / \mathbf{P})$ values measured in milk throughout 2 lactations. The second objective was the confirmation of the effect of milk-specific factors on the outcome of a commercial MAP ELISA. Third, the total IgG concentrations in milk throughout lactation were determined to estimate the effect of milk yield and to identify similar patterns between MAP-specific milk ELISA results and IgG concentration in milk.

\section{MATERIALS AND METHODS}

\section{Herds}

A longitudinal study was performed on 8 selected dairy farms with a history of MAP over a period of 2 yr, as described previously (Eisenberg et al., 2013). One of the 8 herds did not use an automatic cow-recognition system in the milking parlor. Samples of 1,410 cows primarily of the Holstein breed were collected. Testday milk samples were collected of clinically healthy animals the absence of signs of clinical paratuberculosis included. Cow-specific information about parity, date of calving, date of birth, and numbers of milk sampling in current lactation provided by a Dutch breeding company (CRV, Arnhem, the Netherlands) were recorded. The animals were housed in freestall housing systems. Milk MAP ELISA outcomes were communicated to the participating farmers. However, farmers were not obligated to cull MAP ELISA-positive cows during the study.

\section{Milk and Blood Sampling}

Test-day milk samples were collected monthly by CRV and consisted of a mixed sample of the 4 quarters and an equal volume of a morning and afternoon milking. Milk composition (milk volume, fat percentage, total protein percentage, lactose level) and quality (SCC) were analyzed by a commercial milk quality assurance laboratory (Qlip, Zutphen, the Netherlands). Milk samples were subsequently transported to the Faculty of Veterinary Medicine (Utrecht University), and stored at $-20^{\circ} \mathrm{C}$ for a maximum of 3 wk. Samples were analyzed with a commercially available MAP antibody ELISA (Pourquier, Idexx Europe B.V., Hoofddorp, the Netherlands) as described before (Eisenberg et al., 2013). As advised by the manufacturer, an S/P ratio of 40 was used as a cutoff value for a positive test result. If a cow was found to be MAP milk ELISA-positive, a serum blood sample was collected by a veterinarian during the next farm visit within the next month. Blood was collected from the coccygeal vein or artery using a Vacutainer system (BD Vacutainer, BectonDickinson, Erembodegem, Belgium). In the laboratory, serum samples were centrifuged at 1,200 $\times g$ for $15 \mathrm{~min}$ at room temperature. Then, $1 \mathrm{~mL}$ of serum was transferred into a $1.5-\mathrm{mL}$ tube and stored for a maximum of 3 wk at $-20^{\circ} \mathrm{C}$ until further analysis. Serum samples were analyzed using the same MAP-specific antibody ELISA and samples with an $\mathrm{S} / \mathrm{P}$ ratio of 55 or higher were considered MAP-positive according to the recommendations of the manufacturer.

A subset of MAP milk ELISA-positive $(\mathrm{n}=25)$ and ELISA-negative $(n=16)$ cows were selected for total IgG measurement. Positive animals were selected according to the following criteria: cows had a completed lactation that contained between 9 and 12 test-day samplings, had no missing values in their data set, and the animals had at least 2 positive MAP milk ELISA results confirmed by serum ELISA. The number of available serum samples varied per cow, but at least 1 
positive serum sample confirming the MAP milk ELISA was available. Selection criteria for negative cows were the presence of all milk samples of a completed lactation in combination with a MAP milk ELISA-negative outcome for all available milk samples. The selected ELISA-positive animals belonged to 5 herds. Cows had a median $\mathrm{S} / \mathrm{P}$ value of 93.2 (range $=0-428)$. The selected ELISA-negative cows belonged to 4 herds and had a median $\mathrm{S} / \mathrm{P}$ value of 1.5 (range $=0-27.7)$.

\section{Bovine Milk and Serum Total IgG ELISA}

Total IgG concentrations in serum and milk samples were determined using a commercially available ELISA quantitation kit (Bethyl Laboratories Inc., Montgomery, TX) for total bovine IgG. Samples were diluted (milk = $1: 10^{4}$; serum $\left.=1: 10^{5}\right)$ in blocking buffer $(50 \mathrm{~m} M$ Tris, $0.14 M \mathrm{NaCl}, 0.05 \%$ Tween 20, pH 8.0) before assessment of IgG concentrations within the concentration ranges of standards. Analysis was performed according to the manufacturer's manual. Final IgG concentrations $(\mathrm{mg} / \mathrm{mL})$ in milk and serum were calculated using the standard curve generated for each individual assay taking dilutions into account. Total IgG mass in milk was computed using the IgG concentration and milk yield on test day for the individual animal.

\section{Statistical Analysis}

Data editing was done using Excel (Microsoft Office 2010, Microsoft, Redmond, WA) and statistical software package $\mathrm{R}$ (version 2.9.1, R Foundation for Statistical Computing, Vienna, Austria). The descriptive and statistical analyses were done using the SPSS statistical software package (IBM SPSS statistics 20.0, IBM, Armonk, NY). In case of missing milk ELISA results, data of the previous and next sampling were averaged and included in the data file. For graphical presentation of data GraphPad Prism (6.01; GraphPad Software Inc., La Jolla, CA) was used. The partial correlations between milk and serum ELISA results and between milk components and milk yield were determined controlling for repeated measures.

Five mixed model analyses were performed to identify milk-specific factors influencing the MAP milk ELISA and for comparative analysis. For all models, residuals were assessed for normal distribution, constant variance, and a mean of 0 . To correct for repeated observations, test day of sampling and cow were used as a random effect. A variance component structure was used to model the repeated measurements. Variables were assessed for their contribution to the model by the Akaike's information criterion.
To identify milk-specific factors influencing the milk MAP ELISA outcome a model with $\mathrm{S} / \mathrm{P}$ ratio as dependent variable was built. To fulfill model assumptions, $\mathrm{S} / \mathrm{P}$ ratios were natural log-transformed; to include all negative $\mathrm{S} / \mathrm{P}$ ratio results these were set to 0.1 . Classes for milk yield on test day $(\mathrm{kg})$ were established by grouping the cows in equally sized groups based on 10 percentiles $(1:<15.4,2$ : $15.5-18.6,3: 18.7-21.2,4$ : 21.3-23.8, 5: 23.9-26.4, 6: 26.5-29.0, 7: 29.1-31.8, 8: 31.9-35.2, 9: 35.3-40.2, and 10: >40.3) and modeled as a categorical variable. In the full model, the following variables were included: herd, milk yield on test day, DIM (1: 0-30, 2: 31-60, 3: 61-90, 4: 91-120, 5: 121-150, 6: 151-180, 7: 181-210, 8: 211-240, 9: 241-270, and 10: $>271$ ), parity (1: first parity; 2 : second parity; 3 : third parity; 4: fourth parity; and $5: \geq 5$ parity), age on test day (in months; 1: 0-36, 2: 37-48, 3: 49-60, 4: 61-72, and 5: >73), and birth season (summer: May-September; winter: October-April) as categorical variables next to the continuous variables protein $(\% \times 100)$, fat $(\% \times 100), \operatorname{SCC}(\times 1,000)$, and lactose $(\% \times 100)$. In a second run of the model, the variable milk yield on test day was recoded into units of $5 \mathrm{~kg}(1:<5 ; 2: 5.01-10$, 3: 10.01-15, 4: 15.01-20, 5: 20.01-25, 6: 25.01:30, 7: 30.01-35, 8: 35.01-40, 9: 40.01-45, and 10: >45.01) and modeled as a continuous variable; DIM $<30$, first parity, age on test d $0-36$, and birth season summer were used as reference categories.

Milk and serum IgG concentrations and IgG mass determinations per lactation group (DIM) were compared using different models, whereas milk IgG concentrations, milk IgG mass, and serum IgG concentrations served as dependent variables, respectively. Variables health status (0: milk MAP antibody ELISA-negative; 1: milk MAP antibody ELISA-positive) and DIM served as explanatory variables. Days in milk with the lowest milk IgG concentration, milk IgG mass, or serum IgG concentration was considered as reference group, respectively.

The fifth model was used to determine whether the variable milk yield on test day was significantly responsible for the variation in $\operatorname{IgG}$ concentrations in milk. The IgG concentrations in milk served as dependent variable. The categorical variable health status and the continuous variable milk yield served as explanatory variables.

\section{RESULTS}

\section{Herd and Milk Characteristics}

An overview of the herd and milk characteristics expressed as rolling year average of enrolled farms 
Table 1. Overview of farm characteristics

\begin{tabular}{|c|c|c|c|c|c|c|c|c|}
\hline Farm & $\begin{array}{c}\text { No. of } \\
\text { test-day } \\
\text { samplings }\end{array}$ & $\begin{array}{l}\text { No. of cows } \\
(\text { mean } \pm \text { SD })\end{array}$ & $\begin{array}{l}\text { Milk yield }^{1} \\
\quad(\mathrm{~kg})\end{array}$ & $\begin{array}{l}\text { Fat }^{1} \\
(\%)\end{array}$ & $\begin{array}{c}\text { Protein }^{1} \\
(\%)\end{array}$ & $\operatorname{Age}^{1,2}$ & $\begin{array}{c}\text { DIM } \\
(\text { mean } \pm \mathrm{SD})\end{array}$ & $\begin{array}{l}\text { Mean MAP } \\
\text { prevalence }^{3}\end{array}$ \\
\hline 1 & 24 & $95 \pm 5$ & 9,362 & 4.63 & 3.50 & 4.02 & $178 \pm 113$ & 1.0 \\
\hline 2 & 23 & $84 \pm 6$ & 10,158 & 4.38 & 3.50 & 4.10 & $191 \pm 119$ & 1.2 \\
\hline 3 & 25 & $102 \pm 9$ & 9,780 & 4.39 & 3.56 & 4.07 & $194 \pm 132$ & 6.7 \\
\hline 4 & 24 & $78 \pm 4$ & 7,133 & 4.54 & 3.56 & 4.11 & $181 \pm 115$ & 9.0 \\
\hline 5 & 25 & $135 \pm 6$ & 6,999 & 4.50 & 3.53 & 4.09 & $190 \pm 124$ & 4.4 \\
\hline 6 & 25 & $85 \pm 8$ & 8,721 & 4.61 & 3.58 & 4.08 & $181 \pm 119$ & 5.0 \\
\hline 7 & 27 & $111 \pm 7$ & 9,088 & 4.38 & 3.48 & 4.02 & $219 \pm 146$ & 4.0 \\
\hline 8 & 21 & $89 \pm 6$ & 8,639 & 4.55 & 3.54 & 4.04 & $194 \pm 124$ & 13.4 \\
\hline
\end{tabular}

is given in Table 1. The milk ELISA-based apparent MAP prevalence between farms varied between 1 and 13.4\%. Farms were visited 21 to 27 times over a period of $2 \mathrm{yr}$ in the week in which test-day milk samples were collected on the farm. The median test-day interval was $30 \mathrm{~d}$ (28-34 $\mathrm{d}$ for the 25 th and 75 th percentile, respectively) during the sampling period. Of the 194 test-day milk samples measurements, 14 samplings were missed. Therefore, as a missing value correction, 1,351 of 19,090 $\mathrm{S} / \mathrm{P}$ values were estimated using the averaged $\mathrm{S} / \mathrm{P}$ results of previous and next test-day data. Milk yield was significantly negatively correlated with protein $\left(\mathrm{R}^{2}=0.33 ; P<0.00\right)$ and fat $\left(\mathrm{R}^{2}=0.18 ; P<0.00\right)$ concentration. No significant correlation was detected between milk yield and lactose concentration.

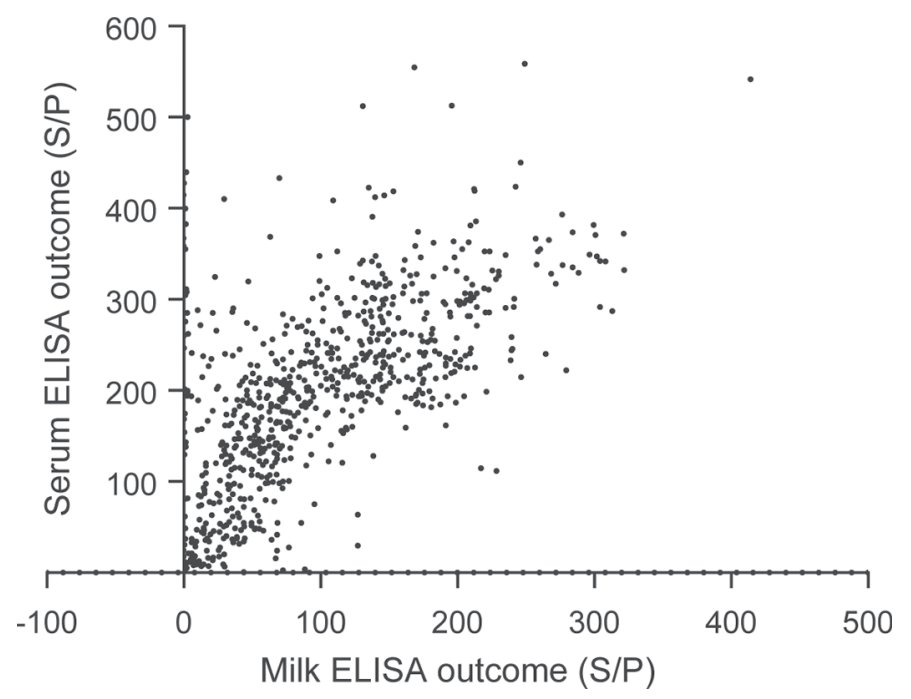

Figure 1. Partial correlation between the outcome of blood and milk ELISA (960 measurements; 199 cows) with an $\mathrm{R}^{2}$ of $0.69(P \leq$ $0.00)$. The cutoff used for milk samples was a sample-to-positive $(\mathrm{S} / \mathrm{P})$ ratio $\geq 40$, and for the blood samples was $\mathrm{S} / \mathrm{P} \geq 55$. Each dot reflects 1 milk and serum result (cows are measured repeatedly).

\section{Antibody-Based Diagnosis of MAP}

An average of 2,402 milk samples (min 1,766; max $3,367)$ and 227 ( $\min 107 ; \max 316)$ serum samples were analyzed per farm during the study period. On average, 98 (range: 78-135) milk samples were screened per visit per farm; of these samples, an average of 5 (range 1-12) tested MAP milk ELISA positive. Prevalence of MAP according to positive milk samples per farm per sampling moment varied between 0 and $17 \%$ and according to serum MAP ELISA between 0 and $15 \%$. The prevalence was significantly different between farms ( $P$ $\leq 0.000)$ and did not significantly change over time. The partial correlation of repeated milk and serum ELISA measurements is shown in Figure 1. In total, 960 positive milk ELISA samples from 199 cows were identified and confirmed by serum ELISA. The correlation between both ELISA outcomes was positive with an $\mathrm{R}^{2}$ of $0.69(P \leq 0.00)$.

\section{Longitudinal Milk MAP ELISA}

The results of repeated sampling of milk yield and MAP S/P ratio during the 2-yr study period were summarized to reflect the relation milk yield versus $\mathrm{S} / \mathrm{P}$ ratio per test day over 2 consecutive lactation periods (Figure 2). In total, 99 cows from which at least 8 testday samples were recorded in 2 lactations spanning a dry period and calving changed from a negative milk MAP S/P to a positive test result during the study. In comparison to the increase in milk yield [mean of 17.7 $\mathrm{kg} / \mathrm{d}(\mathrm{SD}=6.9)$ before dry off to a mean of $32.1 \mathrm{~kg} / \mathrm{d}$ $(\mathrm{SD}=8.6)$ after the first test-day new lactation], the MAP S/P ratio decreased from a mean S/P of 67 (SD $=72$ ) before dry off to a mean $\mathrm{S} / \mathrm{P}$ of 61 (SD 73) at the first test day of the subsequent lactation in the overall data set $(\mathrm{n}=99)$. The average $\mathrm{S} / \mathrm{P}$ ratio at the beginning of the first studied lactation started low (mean $\mathrm{S} / \mathrm{P}=11, \mathrm{SD}=21$ ) and increased during lactation 
(Figure 2A). The same pattern was visible during the second lactation starting at test-day 1 , although the initial mean $\mathrm{S} / \mathrm{P}$ ratio was higher $($ mean $=61, \mathrm{SD}=$ 73 ) at the beginning of the second lactation period and subsequently increased as lactation progressed (Figure $2 \mathrm{~A})$. No gradual increase in the MAP S/P ratio was observed in the 50 cows that did not have any positive test results during the 2-yr follow up. (Figure 2B) When analyzing the different parities separately (Figure $2 \mathrm{C}-\mathrm{F}$ ), the same pattern in the increase of the MAP $\mathrm{S} / \mathrm{P}$ ratios was observed. The first-parity cows tended to have lower $\mathrm{S} / \mathrm{P}$ ratios in the first test-day samples of the lactation (mean $\mathrm{S} / \mathrm{P}=6, \mathrm{SD}=11, \mathrm{n}=40$ ) as compared with second- (mean $\mathrm{S} / \mathrm{P}=15, \mathrm{SD}=25, \mathrm{n}=28$ ), third- (mean $\mathrm{S} / \mathrm{P}=18, \mathrm{SD}=24, \mathrm{n}=17$ ), and higherparity $(\mathrm{S} / \mathrm{P}=16, \mathrm{SD}=22, \mathrm{n}=14)$ cows. Longitudinal follow up of individual milk MAP S/P-positive cows of which also repeated serum samples were taken (n $=199$ ) showed different patterns of antibody presence in both substrates. Figure 3 shows 4 selected examples of response patterns observed during the study; cows $\mathrm{A}$ and $\mathrm{B}$ show an antibody titer pattern with a single switch from test-negative to test-positive. This pattern was observed in the majority of test-positive animals $(>87 \%)$. In some cases, test-positive animals reverted to test-negative for prolonged periods, as exemplified in Figure 3C and D. When analyzing the available data, it was observed that in $12.6 \%$ of the cows tested a single or multiple event of test-negative occurred following testpositive events. In $10 \%$ of the cases, this involved single events most likely due to test-day sampling errors. In $2.0 \%$ of cases, the profile was comparable to the profile observed for cow C (Figure 3). In the remaining cases, the switch could not be confirmed by serum ELISA. The profile observed in cow D (Figure 3) was observed in 1 of 199 cows. None of the animals that switched from test-positive to test-negative showed clinical signs, and all these animals were present until the end of the study.

\section{Mixed Model Analysis}

Variables age on test day, season, fat, and lactose were removed from the full model because they did not improve the fit significantly. Variables milk yield on test day, protein, SCC, DIM, parity, and herd were significant predictors. The variable milk yield on test day included as classes showed a linear negative association with $\mathrm{S} / \mathrm{P}$ ratio. Therefore, milk yield on test day as a continuous variable was included in the final model. Results of the model are displayed in Table 2 . A negative association between the variable milk yield on test day and the natural log-transformed $\mathrm{S} / \mathrm{P}$ ratio was identified indicating that an increase of $5 \mathrm{~kg}$ of milk reduced the natural log-transformed $\mathrm{S} / \mathrm{P}$ ratio by -0.12 . The categorical variable DIM was found to be negatively associated with $\mathrm{S} / \mathrm{P}$ ratio as well, but with a lower impact. No confounding between both variables was present and incorporating both variables in the model improved the fit significantly. The variable herd and SCC were important predictors of the S/P ratio as well and were both positively associated with $\mathrm{S} / \mathrm{P}$ ratio. Protein percentage was found to be positively associated with milk ELISA S/P, but was also identified as a confounder influencing the variable milk yield on test day.

\section{Milk and Serum IgG Concentration}

Mean milk IgG concentrations of $0.42(\mathrm{SD}=0.33)$ and $0.38(\mathrm{SD}=0.32) \mathrm{mg} / \mathrm{mL}$ were detected for MAPnegative $(\mathrm{n}=16)$ and MAP-positive cows $(\mathrm{n}=25)$, respectively. In addition, no significant difference in milk yield between MAP-negative and MAP-positive cows was detected. As MAP-negative and MAP-positive groups did not differ significantly, cows were grouped together for further analysis. Figure 4 displays the results of the IgG concentration measurements in milk and the milk yield throughout lactation. Animals early in lactation (d 0-30) showed high IgG concentrations in milk that decreased when lactation progressed. At the end of lactation the milk IgG concentration increased again, at which point cows between d 241 and 300 in lactation became significantly different from groups in mid lactation. Milk IgG concentration and milk yield showed an inverse pattern. Variance in milk IgG concentration was explained significantly $(P<0.00)$ by milk yield of cows. The serum IgG concentration is displayed in Figure 5. Serum IgG concentrations were constant at the beginning of lactation (until d 151-180). When lactation progressed, serum IgG concentrations increased steadily and showed a significant increase from 241 DIM onward, with exception of lactation group d 301 to 330 .

\section{Milk IgG Mass}

The total $\operatorname{IgG}$ mass in milk is presented in Figure 5 . Mean IgG mass in milk of $10.09 \mathrm{~g} / \mathrm{d}(\mathrm{SD}=8.58)$ for the MAP-negative cows and $10.54 \mathrm{~g} / \mathrm{d}(\mathrm{SD}=5.66)$ for the MAP-positive cows were detected. As no significant difference in excreted IgG mass was noted for MAPnegative and MAP-positive cows, they were grouped for further analysis. The IgG mass excretion in milk differed significantly between the first 90 DIM and the reference lactation group mid lactation (d 180-210). However, when lactation progressed, total IgG mass excretion was found to be stable at a mean of $8.70 \mathrm{~g} / \mathrm{d}$ 
A
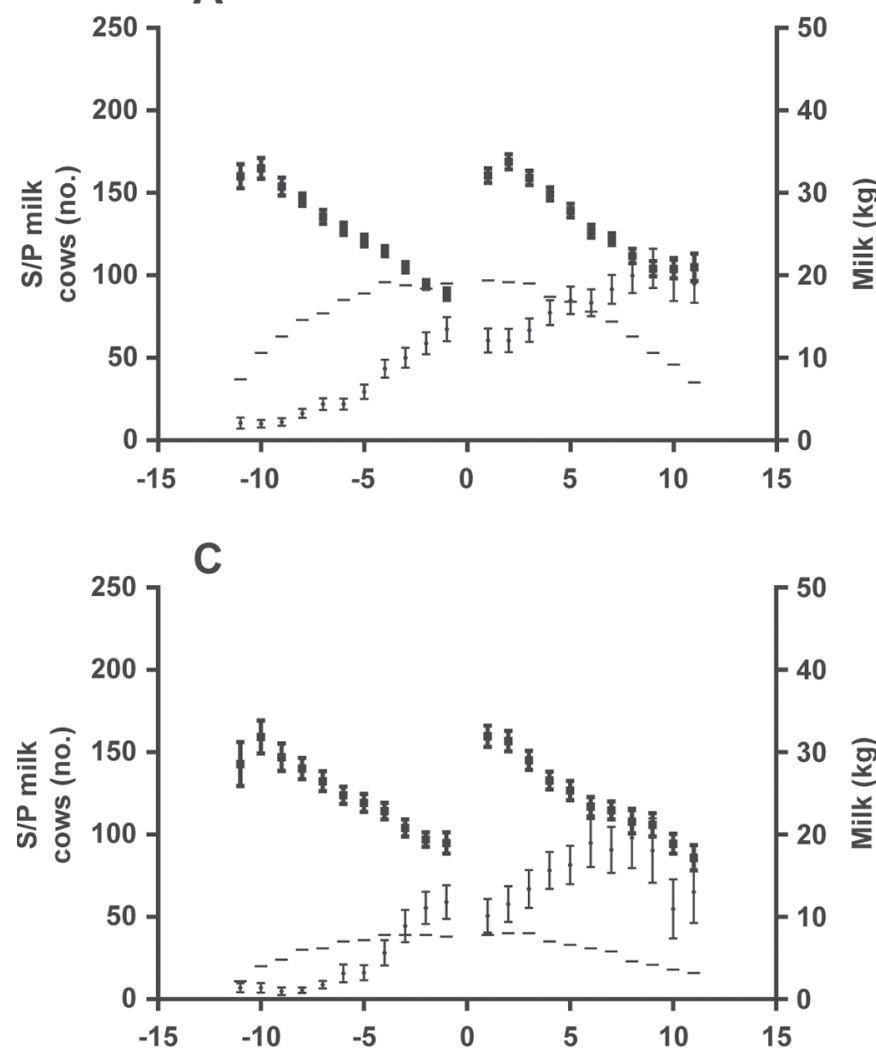

$\mathbf{E}$

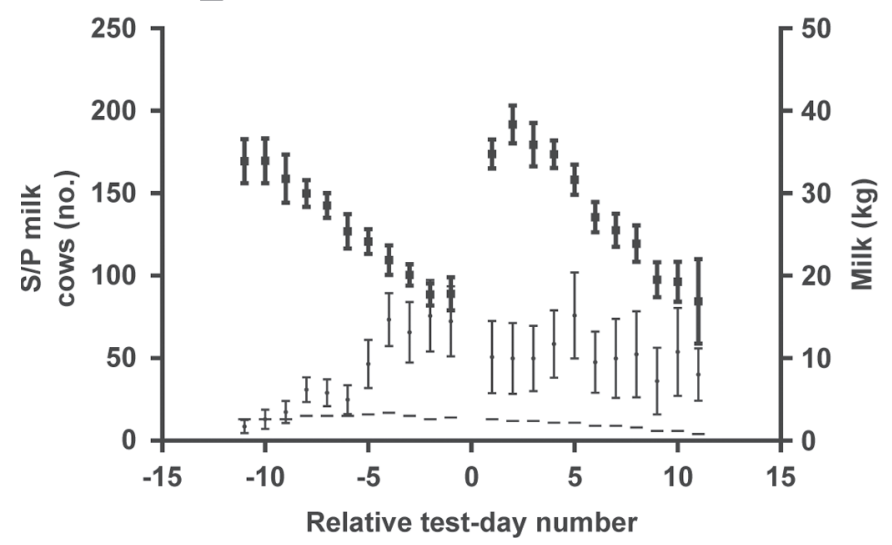

B
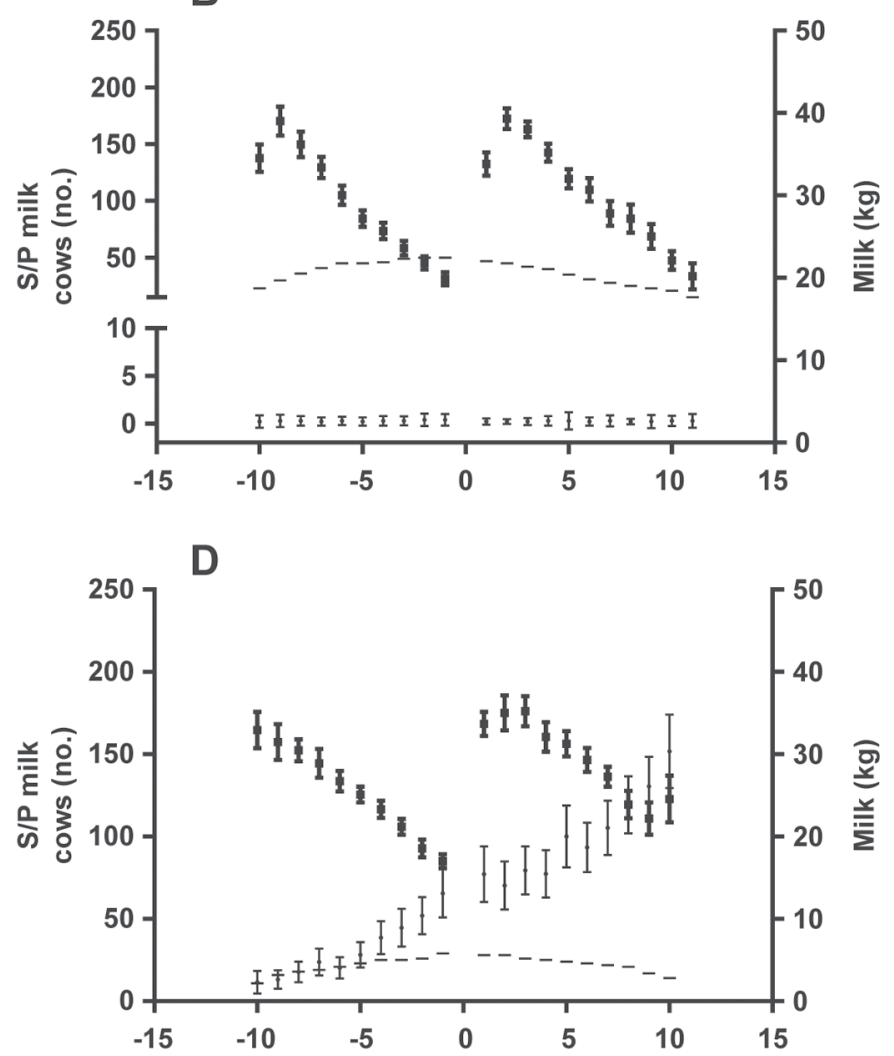

$\mathbf{F}$

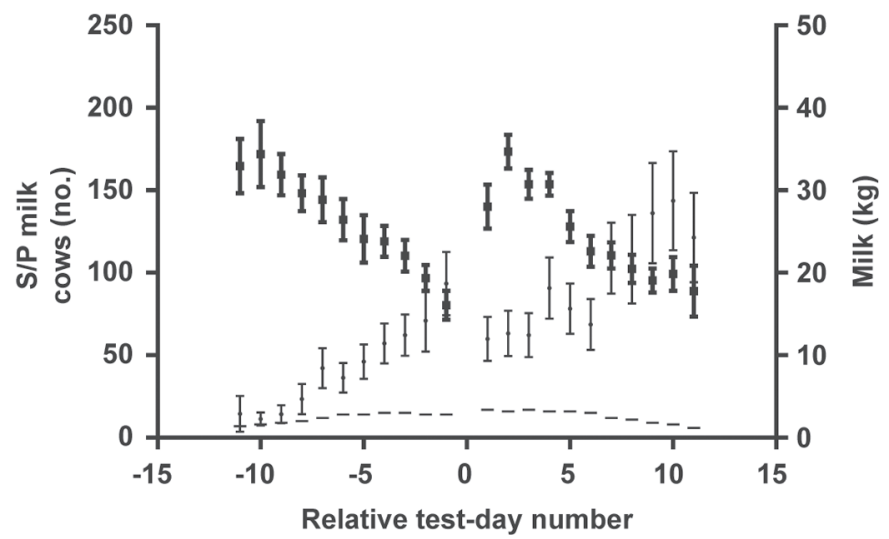

Figure 2. Cows with at least 4 test-day samples before and following a calving were selected from the data set. Panels $\mathrm{A}$ and $\mathrm{C}$ to $\mathrm{F}$ show data of cows that switched from negative to positive Mycobacterium avium ssp. paratuberculosis (MAP)-absorbed ELISA in the test-day milk sample during the observation period and were confirmed with serum ELISA. All test-day milk and ELISA data available from these cows during these lactations were used in constructing the graph. Each panel shows the MAP-absorbed ELISA data as the sample-to-positive (S/P) ratio measured in test-day milk samples, production (kilograms of milk; $\mathbf{-}$ ) at the test day and the number of animals per time point (-). The calving date was set as time point zero and test-day numbers were indicated relative to the calving date. Panel A shows combined test-day data of cows which switched from negative to positive MAP-absorbed ELISA in the test-day milk sample during the observation period irrespective of parity. Panels $\mathrm{C}$ to $\mathrm{F}$ are subsets of the data shown in panel $\mathrm{A}$ and show data from cows going from first to second parity, second to third parity, third to fourth parity, and higher parities, respectively. Panel B shows combined data of cows that remained negative in the MAP-absorbed ELISA in all test-day milk samples during the observation period irrespective of parity.

$(\mathrm{SD}=5.38 \mathrm{~g})$. In contrast to the IgG concentration in milk, the IgG mass remained relatively constant until the end of lactation, with exception of an increased ex- cretion between d 271 and 300, which was significantly higher compared with the reference lactation group. This could be explained partly by the smaller number 

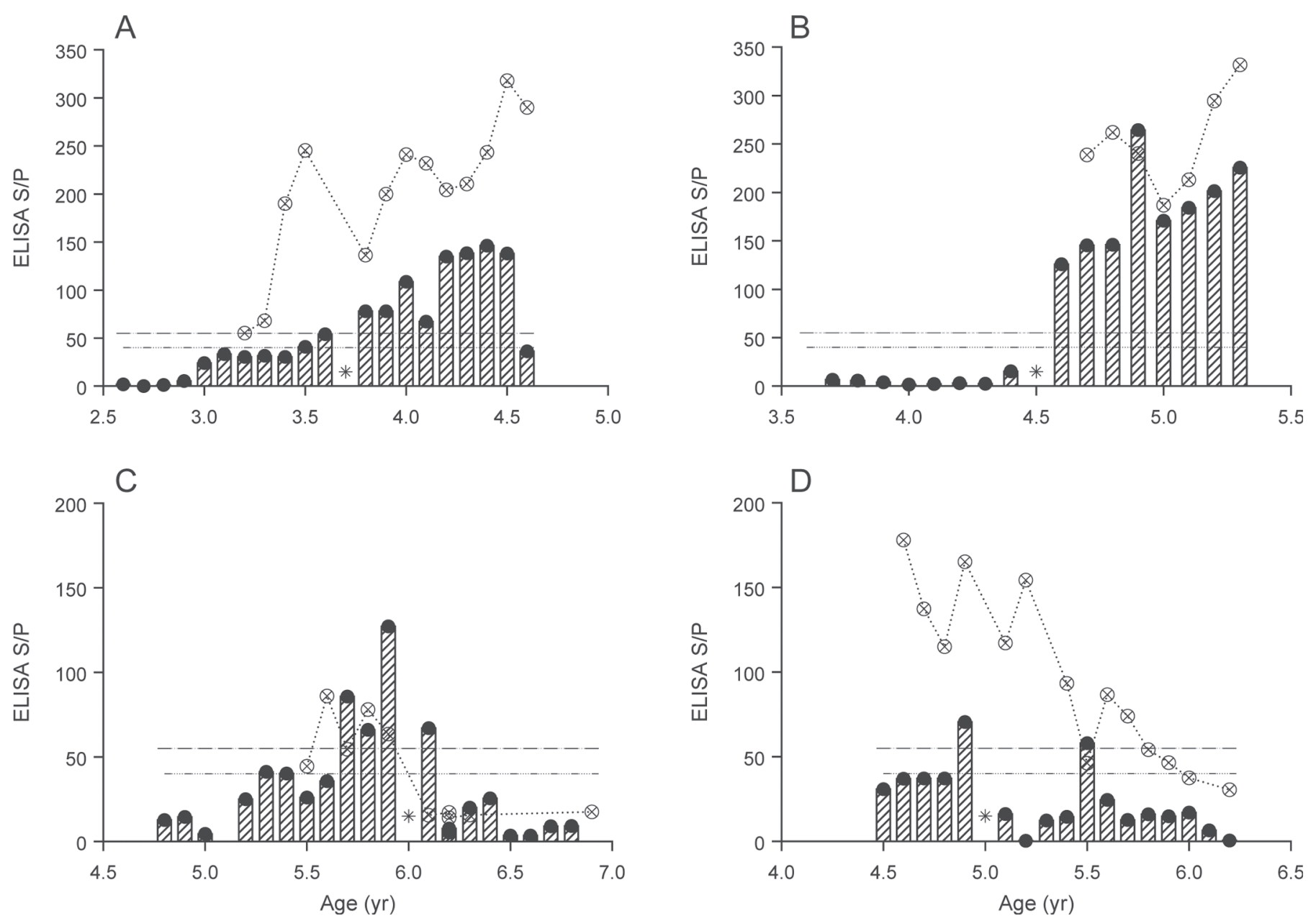

Figure 3. Longitudinal changes of Mycobacterium avium ssp. paratuberculosis (MAP) milk and serum ELISA in relation to age at test day and dry period (parturition) in 4 selected cows. Each measurement reflects a test-day sampling. Bars with black top: sample-to-positive ratio (S/P) milk ELISA; blank circle with cross: S/P serum ELISA; star: end of dry period (parturition); striped line: cutoff value serum ELISA (S/P $=55)$; dotted line: cutoff value milk ELISA $(\mathrm{S} / \mathrm{P}=40)$.

of animals included in this category, leading to more variance in that group, as indicated by the error bars (Figure 5).

\section{DISCUSSION}

There is increasing evidence for the influence of milk yield or lactation stage on the outcome of the MAP diagnosis by milk ELISA (Nielsen et al., 2002a,b; Lombard et al., 2006; Nielsen and Toft, 2012). Hence, several authors have recommended taking milk yield and parity factors into account when interpreting milk ELISA results instead of using a standard cutoff value (Nielsen et al., 2002b; Sanchez et al., 2004; Lombard et al., 2006; Norton et al., 2010; Nielsen and Toft, 2012). The data presented in our study clearly support the notion that intrinsic milk factors, as well as individual cow factors, influence specific MAP milk ELISA test results and endorse the assumption that total $\mathrm{IgG}$ concentration in milk is influenced in a similar way.

The negative association between milk yield and ELISA outcome, which was identified when milk yield was incorporated as a categorical as well as a continuous variable, indicates that on an individual cow level the increase of milk yield may lead to an underestimation of milk ELISA outcome. This is probably due to dilution of antibodies below the detection limit as is suggested in literature (Nielsen and Toft, 2012). The results of our study indicate that for every increase of milk production by $5 \mathrm{~kg}$ the $\mathrm{S} / \mathrm{P}$ ratio has to be multiplied by 0.89 when the other explanatory variables are held constant. Dilution effects probably interfere with MAP antibody detection only in early stages of disease, as repeated samples of milk ELISA positive cows show a steady increase in $\mathrm{S} / \mathrm{P}$ ratio (Figure 2); therefore, antibody titers will exceed the dilution effect 


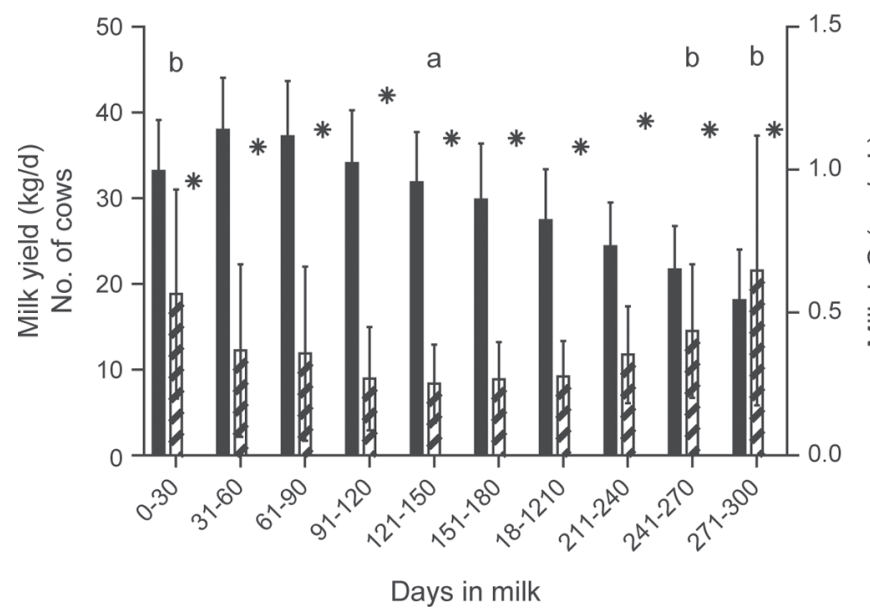

Figure 4. Inverse correlation of mean milk $\operatorname{IgG}$ concentration (striped bars) and mean milk yield throughout lactation (black bars); error bars represent SD. Asterisks represent the number of cows sampled per time point. The letter a represents the reference group for statistical analysis for differences in mean milk $\operatorname{IgG}$ concentration, whereas b represents groups significantly $(P \leq 0.05)$ different from the reference group.

Table 2. Results of the variables of the final linear mixed model predicting the Mycobacterium avium ssp. paratuberculosis (MAP) milk ELISA outcome ${ }^{1}$

\begin{tabular}{lccc}
\hline Item & & & $\begin{array}{c}\text { No. of } \\
\text { animals }\end{array}$ \\
\hline Intercept & -1.082 & $<$-value & $<0.000$ \\
Milk yield on test day & -0.112 & $<0.000$ & 18,594 \\
Protein & 0.004 & $<0.000$ & 18,594 \\
SCC & 0.000 & 0.005 & 18,594 \\
DIM & & & \\
$<30$ & Reference & & 1,668 \\
$31-60$ & -0.018 & 0.721 & 1,622 \\
$61-90$ & -0.139 & 0.007 & 1,657 \\
$91-120$ & -0.155 & 0.003 & 1,641 \\
$121-150$ & -0.297 & $<0.000$ & 1,574 \\
$151-180$ & -0.273 & $<0.000$ & 1,553 \\
$181-210$ & -0.296 & $<0.000$ & 1,503 \\
$211-240$ & -0.410 & $<0.000$ & 1,486 \\
$241-270$ & -0.309 & $<0.000$ & 1,398 \\
$271-300$ & -0.280 & $<0.000$ & 1,332 \\
$>301$ & -0.240 & $<0.000$ & 3,646 \\
Parity & & & \\
1 & Reference & & \\
2 & 0.172 & $<0.000$ & 6,147 \\
3 & 0.465 & $<0.000$ & 4,989 \\
4 & 0.696 & $<0.000$ & 3,541 \\
$\geq 5$ & 0.534 & $<0.000$ & 2,049 \\
Herd & & & \\
1 & Reference & & 2,363 \\
2 & 0.392 & $<0.000$ & 1,798 \\
3 & 1.175 & $<0.000$ & 2,867 \\
4 & 0.392 & $<0.000$ & 1,986 \\
5 & 0.541 & $<0.000$ & 2,771 \\
6 & 0.435 & $<0.000$ & 3,110 \\
7 & 0.686 & $<0.000$ & 2,215 \\
8 & 1.493 & $<0.000$ & 1,980 \\
\hline
\end{tabular}

${ }^{1}$ Milk yield on test day and DIM are negatively correlated with MAP ELISA outcome. $\beta=$ vector of fixed effect.

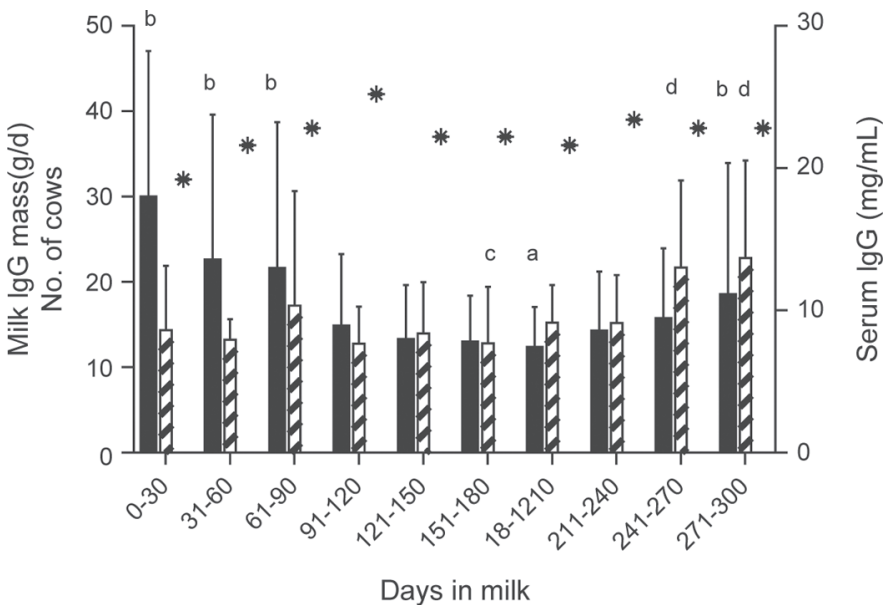

Figure 5. Milk IgG mass (black bars) and serum IgG concentration (striped bars) throughout lactation; error bars represent SD. Asterisks represent the number of cows sampled per time point. The letter a represents the reference group for statistical analysis of differences in mean milk IgG mass; b represents groups significantly $(P \leq 0.05)$ different from the reference group for variable milk IgG mass; $c$ represents the reference group for statistical analysis of differences in mean serum IgG concentration; and d represents groups significantly $(P \leq$ 0.05 ) different from the reference group for serum IgG concentration.

when disease progresses. Milk protein percentage was identified to be positively associated with ELISA S/P ratio. However, as milk yield and protein were negatively correlated and confounding between milk yield and milk protein was identified, the adverse association of protein might be an indirect measure for milk yield. Days in milk was also associated negatively with the outcome of the milk ELISA, as was identified for milk yield only with a lesser magnitude. As no confounding with milk yield was detected, DIM influences the S/P ratio independent of milk yield. Lactation stage has previously been shown to be important for the $\mathrm{S} / \mathrm{P}$ ratio outcome; however, so far only the period up to the first 2 wk of lactation were found to have a higher odds for MAP antibody detection (Nielsen et al., 2002a,b; Zervens et al., 2013). At the beginning of the lactation, milk production is still low and $\operatorname{IgG}$ transfer over the blood-udder barrier might still be higher compared with mid lactation, as is also shown for total $\operatorname{IgG}$ mass present in milk (Figure 4). An increase in IgG mass was again detected at the end of lactation, probably caused by a decrease in milk production.

Although calves generally become infected during their first year of life, paratuberculosis is known to have a long subclinical phase without detectable amounts of MAP-specific antibodies (Chiodini et al., 1984; Clarke, 1997; Sweeney, 2011). This general understanding of disease progression is reflected by the average $\mathrm{S} / \mathrm{P}$ ratio increase in ELISA-positive cows tested repeatedly over time (Figure 2). In addition, the significant estimates 
for all parities compared with parity 1 support earlier findings where cows in parity 1 and 2 have been found to have a lower $\mathrm{S} / \mathrm{P}$ ratio compared with older animals; therefore, they are less likely identified by milk ELISA (Nielsen and Toft, 2012). For the same reason, age on test day was inserted into the model to identify the variation caused by age during our 2-yr trail. However, age was found not to contribute significantly to the model, probably because this variable is strongly correlated with parity. Within-herd prevalence is known to influence sensitivity of the MAP milk ELISA (Lavers et al., 2014); this was confirmed by the significant influence of the variable herd on the MAP milk ELISA outcome. The reference farm chosen had hardly any cases of milk ELISA-positive cows throughout the study period. On farms with a higher MAP prevalence it is more likely that cows are identified as MAP-positive using the milk ELISA. Somatic cell count was also identified as a significant predictor for MAP milk ELISA outcome. In the literature, a correlation between SSC and MAP infection has been discussed, with several studies conducted showing conflicting results (Merkal et al., 1975; McNab et al., 1991; Wilson et al., 1993; Lombard et al., 2005). It has been hypothesized that diagnostic sensitivity of the used test combined with the disease stage of the enrolled cows lead to the different study outcomes (Hutchinson, 1996).

Repeated sampling over a 2-yr period, with no obligatory management measures dictated by a positive ELISA outcome, helped to build unique MAP antibody profiles in milk and serum of individual cows throughout lactation. In particular, the relation between seroconversion and parturition could be examined (Figure 3). The majority of cows had a profile as expected starting out milk ELISA-negative. When milk ELISA outcome became positive, serum ELISA usually confirmed the infection and cows stayed positive for the rest of the study period with increasing antibody titers (Figure 3A, B). In cases when cows were detected milk ELISA-positive but the outcome could not be confirmed by serum ELISA, a sampling error during the collection of test-day samples probably occurred. The majority of these cases occurred on a farm without an automated cow-recognition system, indicating that farm management systems are important for reliable sampling and interpretation. However, several cows $(2 \%)$ had antibody profiles in milk and serum that are hard to explain with today's understanding of the MAP-induced immune response in cattle (Figure 3C). Cows were identified as MAP-positive by milk ELISA and serology confirmed the diagnoses repeatedly. After parturition the antibody level decreased again until undetectable levels were reached. This might be due to a return to a steady state with a decrease of antibody titers under the detection level or might indicate that a transient infection of paratuberculosis in adult cattle exists. Transient MAP shedding due to uptake of MAP from the environment has been described (Sweeney et al., 1992), which may also lead to a transient antibody response, although this has not been documented previously. One cow was detected continuously ELISA-positive in serum without the presence of MAP antibodies in milk (Figure $3 \mathrm{~d}$ ). Why no detectable MAP-specific antibody titers were translocated into the udder in this cow is unclear. These monthly longitudinal data show that not all cows follow the same kinetic path of antibody response during infection, and that a substantial number of sampling errors can occur during routine test-day sampling. Therefore, a decision for culling of individual cows based on a single measurement has serious drawbacks as opposed to repeated measurements.

Similar to changes in MAP-specific antibodies throughout lactation, little is known about longitudinal changes in total IgG concentration in milk and serum during lactation. So far, one study was published which followed 6 cows during lactation and determined a change in immunoglobulin concentration in mammary secretions; however, no link with milk yield was established (Guidry et al., 1980). Mean concentrations of IgG in milk throughout lactation have been investigated and described to be similar to the values determined in our study (Liu et al., 2009). The results presented here show that the total IgG concentration curve in milk opposes the curve of milk yield (Figure 4) as was found for the MAP-specific antibodies and was supported by the mixed model analysis. Although the significantly higher IgG excretion at the beginning and the end of lactation could be partly explained by the smaller number of animals included in this category and therefore lead to more variance in that group. However, this finding might also support the suggestion to use milk at the beginning or the end of lactation for ELISA testing to improve the test performance. This corresponds with the kinetics described for specific antibodies against Ostertagia ostertagi and IgG, although in that study cross-sectional data were used (Sanchez et al. 2004). Furthermore, the relatively constant IgG mass excretion per day following the lactation peak (Figure 4) indicates that antibodies are excreted at a constant rate into milk and that the process is not influenced by the final milk antibody concentration. An earlier study, however, found that IgG mass and lactation stage were positively correlated indicating an increase in IgG excretion during lactation (Liu et al., 2009). Their finding might be explained by the fact that cows were only divided into 4 milk yield classes compared with the longitudinal design with 12 lactation groups presented here. The IgG present in milk 
has its origin in serum and is known to be translocated over the blood-udder barrier (Larson et al., 1980). The exact mechanism behind the excretion or secretion of IgG and other subclasses of antibodies into milk and whether selection occurs is still unclear (Butler, 1983; Baumrucker et al., 2010). It has been hypothesized that $\operatorname{IgG}$ present in milk is translocated from serum via the neonatal Fc receptor, which can be found in ducts and acini basolateral on the mammary epithelial cell in cattle (Cervenak and Kacskovics, 2009). Differences in $\operatorname{IgG}_{1}$ and $\mathrm{IgG}_{2}$ translocation occur due to differences in binding ability of the immunoglobulin to the receptor. Redistribution of the receptors to the apical side of the cell around calving makes the selective concentration of $\mathrm{IgG}_{1}$ during colostrum formation possible (Mayer et al., 2002,2005 ), which is necessary to provide the calf with sufficient maternal immunoglobulins. During our study, IgG serum titers increased significantly when lactation progressed with a significant increase of $\mathrm{IgG}$ in milk at the end of the lactation.

\section{CONCLUSIONS}

In conclusion, our results suggest that the concentration of MAP-specific antibodies in milk is strongly influenced by changes in milk yield. In addition, as cows have a relatively constant excretion of IgG in milk, the variation in $\operatorname{Ig} G$ concentration in milk seems also liable to dilution through milk yield. This supports the assumption that kinetics is influenced similarly. Therefore, infected cows with a high milk yield are more likely to test negative. In addition, first-parity cows with lower MAP titers are more likely to be missed. When test frequency in a MAP-control program is once a year, and assuming that approximately one-third of a herd experiences its lactation peak and half of the herd is first parity, the success of the MAP-control program might be considerably impaired when a milk ELISA is used for MAP screening. To reduce this problem, shortening the test interval between tests or performing milk ELISA tests only in early or late lactation, when milk yield is low, should be considered. From a management point of view, sampling should preferentially be done during early lactation before cows are bred again. Based on the slow progressive infection dynamics, only first-parity cows should be tested at the end of their first lactation to avoid false-negative results.

\section{ACKNOWLEDGMENTS}

The authors thank the participating farmers for their hospitality during the sampling period. The authors are grateful to Marina Bouman (Teelin Petfood B. V., Hoogeveen, the Netherlands) and Sander Prins and Jasper van den Broek (Utrecht University) for their assistance with laboratory work. Also, Wiebren Santema (Ampart BV, Barchem, the Netherlands) and Jan van den Broek (Utrecht University) are thanked for their feedback on study design and statistics. Special thanks go out to Kimm van Hulzen (Radboud UMC, Nijmegen, the Netherlands) for her assistance with the statistical analysis. Furthermore, the authors are appreciative for the support of CRV (Arnhem, the Netherlands) by supplying the raw data of test-day sample analysis. The study was partly funded by Stichting Mesdagzuivelfonds (NLTO, Leeuwarden, The Netherlands).

\section{REFERENCES}

Baumrucker, C. R., A. M. Burkett, A. L. Magliaro-Macrina, and C. D. Dechow. 2010. Colostrogenesis: Mass transfer of immunoglobulin G1 into colostrum. J. Dairy Sci. 93:3031-3038.

Butler, J. E. 1983. Bovine immunoglobulins: An augmented review. Vet. Immunol. Immunopathol. 4:43-152.

Cervenak, J., and I. Kacskovics. 2009. The neonatal Fc receptor plays a crucial role in the metabolism of IgG in livestok animals. Vet. Immunol. Immunopathol. 128:171-177.

Chiodini, R. J. 1996. Immunology: Resistance to paratuberculosis. Vet. Clin. North Am. Food Anim. Pract. 12:313-343.

Chiodini, R. J., H. J. Van Kruiningen, and R. S. Merkal. 1984. Ruminant paratuberculosis (Johne's disease): The current status and future prospects. Cornell Vet. 74:218-262.

Clark, D. L., Jr., J. J. Koziczkowski, R. P. Radcliff, R. A. Carlson, and J. L. Ellingson. 2008. Detection of Mycobacterium avium subspecies paratuberculosis: Comparing fecal culture versus serum enzyme-linked immunosorbent assay and direct fecal polymerase chain reaction. J. Dairy Sci. 91:2620-2627.

Clarke, C. J. 1997. The pathology and pathogenesis of paratuberculosis in ruminants and other species. J. Comp. Pathol. 116:217-261.

Eisenberg, S. W., R. Chuchaisangrat, M. Nielen, and A. P. Koets. 2013. Relationship between presence of cows with milk positive for Mycobacterium avium ssp. paratuberculosis-specific antibody by enzyme-linked immunosorbent assay and viable $M$. avium ssp. paratuberculosis in dust in cattle barns. Appl. Environ. Microbiol. 79:5458-5464.

Guidry, J., J. E. Butler, R. E. Pearson, and B. T. Weinland. 1980. IgA, igG1, IgG2, IgM, and BSA in serum and mammary secretion throughout lactation. Vet. Immunol. Immunopathol. 1:329-341.

Hutchinson, L. J. 1996. Economic impact of paratuberculosis. Vet. Clin. North Am. Food Anim. Pract. 12:373-381.

Larson, B. L., H. L. Heary Jr., and J. E. Devery. 1980. Immunoglobulin production and transport by the mammary gland. J. Dairy Sci. 63:665-671.

Lavers, C. J., H. W. Barkema, I. R. Dohoo, S. L. B. McKenna, and G. P. Keefe. 2014. Evaluation of milk ELISA for detection of $M y$ cobacterium avium subspecies paratuberculosis in dairy herds and association with within-herd prevalence. J. Dairy Sci. 97:299-309.

Liu, G. L., J. Q. Wang, D. P. Bu, J. B. Cheng, C. G. Zhang, H. Y. Wei, L. Y. Zhou, Z. F. Zhou, H. Hu, and X. L. Dong. 2009. Factors affecting the transfer of immunoglobulin G1 into the milk of Holstein cows. Vet. J. 182:79-85.

Lombard, J. E., T. M. Byrem, B. A. Wagner, and B. J. McCluskey. 2006. Comparison of milk and serum enzyme-linked immunosorbent assays for diagnosis of Mycobacterium avium subspecies paratuberculosis infection in dairy cattle. J. Vet. Diagn. Invest. 18:448-458.

Lombard, J. E., F. B. Garry, B. J. McCluskey, and B. A. Wagner 2005. Risk of removal and effects on milk production associated with paratuberculosis status in dairy cows. J. Am. Vet. Med. Assoc. 227:1975-1981. 
Mattsson, R., and A. Mattsson. 1984. Immunoglobulin-secreting cells in various maternal lymphoid tissues during syngeneic and allogeneic murine pregnancy. Dev. Comp. Immunol. 8:921-929.

Mayer, B., M. Doleschall, B. Bender, J. Bartyik, Z. Bosze, L. V. Frenyo, and I. Kacskovics. 2005. Expression of the neonatal Fc receptor $(\mathrm{FcRn})$ in the bovine mammary gland. J. Dairy Res. 72:107-112.

Mayer, B., A. Zolnai, L. V. Frenyo, V. Jancsik, Z. Szentirmay, L. Hammarstrom, and I. Kacskovics. 2002. Redistribution of the sheep neonatal Fc receptor in the mammary gland around the time of parturition in ewes and its localization in the small intestine of neonatal lambs. Immunology 107:288-296.

McNab, W. B., A. H. Meek, J. R. Duncan, B. W. Brooks, A. A. Van Dreumel, S. W. Martin, K. H. Nielsen, E. A. Sugden, and C. Turcotte. 1991. An evaluation of selected screening tests for bovine paratuberculosis. Can. J. Vet. Res. 55:252-259.

Merkal, R. S., A. B. Larsen, and G. D. Booth. 1975. Analysis of the effect of inapparent bovine paratuberculosis. Am. J. Vet. Res. 36:837-838.

Morin, D. E., S. V. Nelson, E. D. Reid, D. W. Nagy, G. E. Dahl, and P. D. Constable. 2010. Effect of colostral volume, interval between calving and first milking, and photoperiod on colostral IgG concentrations in dairy cows. J. Am. Vet. Med. Assoc. 237:420-428.

Naser, S. A., G. Ghobrial, C. Romero, and J. F. Valentine. 2004. Culture of Mycobacterium avium subspecies paratuberculosis from the blood of patients with Crohn's disease. Lancet 364:1039-1044.

Nielsen, S. S. 2008. Transitions in diagnostic tests used for detection of Mycobacterium avium ssp. paratuberculosis infections in cattle. Vet. Microbiol. 132:274-282.

Nielsen, S. S., C. Enevoldsen, and Y. T. Grohn. 2002a. The Mycobacterium avium ssp. paratuberculosis ELISA response by parity and stage of lactation. Prev. Vet. Med. 54:1-10.

Nielsen, S. S., Y. T. Grohn, and C. Enevoldsen. 2002b. Variation of the milk antibody response to paratuberculosis in naturally infected dairy cows. J. Dairy Sci. 85:2795-2802.
Nielsen, S. S., and N. Toft. 2012. Effect of days in milk and milk yield on testing positive in milk antibody ELISA to Mycobacterium avium ssp. paratuberculosis in dairy cattle. Vet. Immunol. Immunopathol. 149:6-10.

Norton, S., W. O. Johnson, G. Jones, and C. Heuer. 2010. Evaluation of diagnostic tests for Johne's disease (Mycobacterium avium subspecies paratuberculosis) in New Zealand dairy cows. J. Vet. Diagn. Invest. 22:341-351.

Ott, S. L., S. J. Wells, and B. A. Wagner. 1999. Herd-level economic losses associated with Johne's disease on US dairy operations. Prev. Vet. Med. 40:179-192.

Sanchez, J., F. Markham, I. Dohoo, J. Sheppard, G. Keefe, and K. Leslie. 2004. Milk antibodies against Ostertagia ostertagi: Relationships with milk $\operatorname{IgG}$ and production parameters in lactating dairy cattle. Vet. Parasitol. 120:319-330.

Sweeney, R. W. 2011. Pathogenesis of paratuberculosis. Vet. Clin. North Am. Food Anim. Pract. 27:537-546. (v.)

Sweeney, R. W., R. H. Whitlock, A. N. Hamir, A. E. Rosenberger, and S. A. Herr. 1992. Isolation of Mycobacterium paratuberculosis after oral inoculation in uninfected cattle. Am. J. Vet. Res. 53:1312-1314.

Villarino, M. A., H. M. Scott, and E. R. Jordan. 2011. Influence of parity at time of detection of serologic antibodies to Mycobacterium avium subspecies paratuberculosis on reduction in daily and lifetime milk production in Holstein cows. J. Anim. Sci. 89:267-276.

Wilson, D. J., C. Rossiter, H. R. Han, and P. M. Sears. 1993. Association of Mycobacterium paratuberculosis infection with reduced mastitis, but with decreased milk production and increased cull rate in clinically normal dairy cows. Am. J. Vet. Res. 54:1851-1857.

Zervens, L. M., S. S. Nielsen, and G. Jungersen. 2013. Characterisation of an ELISA detecting immunoglobulin $\mathrm{G}$ to Mycobacterium avium ssp. paratuberculosis in bovine colostrum. Vet. J. 197:889-891. 